\title{
Three bufadienolides-induced human lung cancer CL1-5 cell death mainly through autophagy
}

Hui-Chi Huang ${ }^{1}$, Meng-Shiou Lee ${ }^{1}$, Wen-Te Chang ${ }^{1}$, Hsing-Yu Chen ${ }^{1}$, Yu-Hua Chen ${ }^{1}$, Chi-Chen Lin ${ }^{2}$, Ming-Kuem Lin ${ }^{1, *}$

${ }^{1}$ Department of Chinese Pharmaceutical Sciences and Chinese Medicine Resources, College of Chinese Medicine, China Medical University, Taichung, Taiwan.

${ }^{2}$ Institute of Medical Technology, College of Life Science, National Chung Hsing University, Taichung, Taiwan.

*Corresponding authors:

Ming-Kuem Lin

Tel: (886) 4-2205-3366 (ext. 5212), E-mail: linmk@mail.cmu.edu.tw

Department of Chinese Pharmaceutical Sciences and Chinese Medicine Resources, College of

Biopharmaceutical and Food Sciences, China Medical University, No. 91, Hsueh-Shih Road, Taichung,

Taiwan. 


\section{Abstract}

Lung cancer is almost the most common cause of cancer death in the world. Clinically, the conventional therapy to eradicate the cancer cells is chemotherapy but a better drug remains required. In this study, the effects of three bufadienolides, kalantuboside B, kalantuboside A and bryotoxin C, isolated from Kalanchoe tubiflora (Harvey) were evaluated and characterized in CL1-5 highly metastatic human lung cancer cells. Contrary to the apoptosis-promoting activity in other cancer cells, these three bufadienolides did not induce apoptosis in CL1-5 cancer cells. Instead, they activated an autophagy pathway, as indicated by the increase of autophagosomes formation. The induction of autophagy by these three bufadienolides was demonstrated to link to down-regulation of p-mTOR as well as up-regulation of LC3-II, ATG5, ATG7, Beclin-1. Moreover, among these three compounds, kalantuboside B in which a monosaccharide is attached at the bufadienolide aglycon, exhibited a better autophagy induction. Our findings revealed an alternative mechanism of drug action by bufadienolides in lung cancer cells and provided evidence for the possibility of treating highly metastatic human lung cancer through an autophagy pathway.

KEYWORDS: Kalanchoe tubiflora, bufadienolide, CL1-5 human lung cancer cells, autophagy 


\section{Introduction}

Bufadienolides are characterized by the presence of C-24 steroid structure and a six-membered lactone ( $\alpha$-pyrone) ring located at $\mathrm{C}-17 \beta[1]$. They have been found and isolated from plant and animal sources [1,2]. Pharmaceutical studies showed that bufadienolides possess potent anticancer activity. For example, bufalin has been demonstrated to induce apoptosis in gastric cancer MGC803 cells [3]. Bufalin induced apoptosis in human leukemia cells $[4,5]$. Cinobufagin induced apoptosis in human breast cancer MCF-7 cell [6]. Bufalin was also demonstrated to increase expressions of autophagy markers, Beclin 1 and LC3II in hepatocellular carcinoma HepG2 cells [7]. Bufalin and cinobufagin induced apoptosis of HepG2 cells through both Fas- and mitochondria-mediated pathways [8]. Bufalin induced autophagy through Akt/mTOR pathway and apoptosis in liver cancer SK-HEP-1 cells [9]. In vivo examination of anti-human hepatocellular carcinoma in nude mice, bufalin exhibited a tumor inhibitory effect [10]. Bufalin induced apoptosis in human lung cancer NCI-H460 cells and exhibited the activity against human lung cancer xenografts [11]. Cinobufagin induced intrinsic apoptosis through AKT signaling pathway in human non-small cell lung cancer cells, including A549, H1299, H460, and SK-MES-1 [12]. In the clinical cases, $40 \%$ of patients suffer from a stage III or IV of non-small cell lung cancer, pancreatic cancer or hepatocellular carcinoma maintained a stable disease with the treatment of bufadienolidescontaining toad venom [13]. Interestingly, bufalin only triggered autophagy in human colon cancer HT-29 and Caco-2 cells [14]. It is indicated that bufadienolides can induce apoptosis- or/and autophagymediated cell death in different cancer cells. However, the molecular pathways triggered by 
bufadienolides seems various in different cancer cells.

Lung carcinoma is the most or second common cause of cancer-related deaths worldwide. In the clinic, although there are several therapeutic drugs such as Gefitinib and Erlotinib, an intrinsic or acquired resistance often occur $[15,16]$. Thus, it is necessary to develop an effective chemotherapeutic drug to treat lung carcinoma. Moreover, no report elucidates the effect of bufadienolides on highly metastatic human non-small cell lung cancer cells, CL1-5. To discover the good candidate drug for the lung cancer therapy, in this present study, three bufadienolides were used to examine and compare their anticancer activities and explore the underlying mechanism of the cell death in the three bufadienolides-treated human lung cancer CL1-5 cells.

\section{Materials and methods}

2.1. Cell culture

CL1-5 highly metastatic human lung cancer cell line was kindly provided by Dr. C.C. Lin from National Chung Hsing University, Taiwan. Low-glucose Dulbecco's modified Eagle's medium with 1\% penicillin-streptomycin and 10\% FBS (Gibco Life Technologies, Grand Island, NY, USA) were used as growth medium. Cells were cultured at $37^{\circ} \mathrm{C}$ with $5 \%$ carbon dioxide. Cells at passages 4 to 16 were used for the examinations. 


\subsection{Bufadienolides}

Three bufadienolides, kalantuboside B, kalantuboside A and bryotoxin C (Fig. 1), used in this study were isolated from Kalanchoe tubiflora (Harvey) as described previously [17].

\subsection{Cell viability assay}

CL1-5 cells were seeded into 24 -well plates $\left(10^{4}\right.$ cells each well) in $1 \mathrm{ml}$ of growth medium and incubated overnight before drug treatments. Cell viability was determined using a colorimetric 3-(4,5dimethylthiazol-2-yl)-2,5-diphenyltetrazolium (MTT; Sigma Chemical Co., St. Louis, MO, USA) assay as described previously [18].

\subsection{Annexin V/PI analysis}

CL1-5 cells were seeded into 6-well plates. 0.05\% trypsin-EDTA (Gibco, Gaithersburg, MD, USA) were used to detach the cell layer after drug treatments. The cell pellet was resuspended in PBS then stained with PI/Annexin V solution in the dark for 20 minutes according to the manual protocol (Invitrogen, Carlsbad, CA, USA). The treated cells were then analyzed by flow cytometry.

2.5. Cell cycle analysis

After drug treatments, CL1-5 cells were harvested and fixed with $70 \%$ methanol in PBS at $4{ }^{\circ} \mathrm{C}$ overnight. Cells were washed twice to ensure removal of methanol before stained with PI and RNase. 
Samples then put on flow cytometry after 30 minutes of PI staining.

2.6. Acridine orange staining analysis

CL1-5 cells were plated in 6-well for 24 hours before drug treatments. After drug treatments, acridine orange was added into culture medium with a working concentration of $10 \mu \mathrm{g} / \mathrm{ml}$. Cells were incubated with acridine orange for 15 minutes and then analyzed by flow cytometry immediately.

2.7. LC3II puncta formation assay

LC-3II puncta formation assay was performed as described previously [18]. Briefly, CL1-5 cells were transfected with p-GFP-LC3 plasmids and then treated with vehicle or three compounds (100 nM) for $24 \mathrm{~h}$, respectively. The green fluorescent LC3II puncta formation was observed under confocal microscopy.

2.8. Western blotting analysis

CL1-5 cells were plated in 6-cm dishes for 24 hours before drug treatments. After treatment with these three compounds, the harvested cells were lysed with RIPA buffer (Thermo Fisher Scientific, Waltham, MA, USA). The protein concentration was determined using a BCA kit (Thermo Fisher Scientific). Equal amounts of the proteins were separated by SDS-PAGE. The proteins were then electrotransferred to PVDF membranes (Millipore, Temecula, CA, USA) and detected by different 
specific antibodies and secondary antibodies linked horseradish peroxidase. The membranes were developed using an enhanced chemiluminescence (ECL) system (Thermo Fisher). The detected protein bands were imaged by luminescence machine. The intensity of protein bands was quantified using Image J Software. The folds of the changes were calculated by dividing the intensity of the protein bands of the experimental group by those of control group.

\section{Results}

3.1. Kalantuboside B (KB), kalantuboside A (KA) and bryotoxin C (BC) reduce cell viability in human lung cancer CL1-5 cells

The CL1-5 human lung adenocarcinoma cells were used and the effects of KB, KA, BC treatment on CL1-5 cell viability were firstly examined with MTT assay. The results showed that the cell viabilities were inhibited by these three compounds in a dose-dependent manner. The $\mathrm{IC}_{50}$ for $24 \mathrm{hr}$ of KB, KA and BC treatment in CL1-5 cells was $52.30 \pm 1.8 \mathrm{ng} / \mathrm{ml}(90.8 \mathrm{nM}), 70.56 \pm 5.7 \mathrm{ng} / \mathrm{ml}(114.18 \mathrm{nM})$ and $76.70 \pm$ $1.3 \mathrm{ng} / \mathrm{ml}$ (162.49 nM), respectively (Fig. 2).

3.2. KB, KA and BC almost did not induce apoptosis

Apoptosis is a most common process of cell death. Thus, apoptosis induction by these three compounds was examined using Annexin V/PI analyses. Surprised, no significant apoptotic cells could be 
detected (Fig. 3).

3.3. Only KB slightly induced G2/M cell cycle arrest

Cell cycle arrest is also a process of cell death. Cell cycle arrest by these three compounds was next examined. Interestingly, no significant cell cycle arrest could be observed in the KA- and BC- treated cells and only a slight increase of G2/M stage cells was observed in the KB-treated cells (Fig. 4). In addition, no obvious subG1 stage cell which represents apoptotic cell was detected. This result is consistent with that in the Annexin V/PI analyses. Since the slightly or no effect of three compounds on the cell cycle of the treated cells, it is expected that the contribution of the CL1-5 cell death would be another pathway.

3.4. $\mathrm{KB}, \mathrm{KA}$ and $\mathrm{BC}$ increased autophagosomes

Autophagy process was next examined. CL1-5 cells were treated with KB, KA and BC for 24hrs, respectively, the cells were then stained with $1 \mu \mathrm{g} / \mathrm{ml}$ of acridine orange to observe the autophagosome caused by cellular autophagy using flow cytometry. Interestingly, the results showed that $14.45,12.29$ and $11.35 \%$ of cells exhibit greater autophagosomes after $100 \mathrm{nM}$ of $\mathrm{KB}, \mathrm{KA}$ and $\mathrm{BC}$ treatment, respectively (Fig. 5). 


\subsection{LC3 puncta formation in KB- and KA-treated CL1-5 cells}

The increase of LC3 (microtubule-associated protein light chain 3) puncta is a promising indication for the induction of autophagosomes $[19,20]$. When autophagosomes are started to form, LC3-II will be increased and rescued to form the membrane of autophagic vesicles, results in the formation of punctate structures within the cytoplasm [20]. To confirm KB, KA and BC induce cellular autophagy, the LC3 aggregation was examined using overexpressing LC3-GFP fusion proteins in CL1-5. The plasmid contained with LC3-GFP was transfected into CL1-5 cells and the cells were treated with $100 \mathrm{nM}$ of KB, $\mathrm{KA}$ and $\mathrm{BC}$ as well as $50 \mu \mathrm{M}$ of the positive control rapamycin for $24 \mathrm{hrs}$, respectively. Using confocal microscopy, puncta structure formation was observed in the cells treated with $\mathrm{KB}, \mathrm{KA}$ and the positive control rapamycin, but was not easy to be observed in the cells treated with BC (Fig. 6). Also, the puncta formation was much highly induced by KB than KA.

3.6. KB, KA and BC down-regulated p-mTOR and up-regulated LC3-II, Beclin-1, Atg5 and Atg7 in CL15 cells

Down-regulation of p-mTOR and up-regulation of LC3-II, Beclin-1, Atg5 and Atg7 have been shown to activate cellular autophagy $[21,22]$. Thus, in order to elucidate the molecular effect, the levels of these proteins were examined by western blot analyses. As shown in Fig. 7, the level of p-mTOR was reduced and the levels of LC3-II, Beclin-1, Atg5 and Atg7 were increased by these three compounds and rapamycin. In addition, KB always exhibited higher activity. 


\section{7. $\mathrm{KB}, \mathrm{KA}$ and $\mathrm{AB}$ decreased $\mathrm{p} 62$ in CL1-5 cells}

p62 which is also named sequestosome 1 is a LC3-binding protein and a receptor for the cargo destined to be degraded by ubiquitinated proteins. As the autophagy-mediated degradation progresses, p62 is degraded by autophagy [23]. To elucidate this phenomenon, p62 was next detected. As shown in Fig. 8, the level of p62 were reduced in the CL1-5 cells treated with KB, KA, BC and rapamycin, confirming that these three compounds indeed induce cellular autophagy-mediated degradation process in the CL1-5 cells. In order to further confirm the autophagy induced by these three compounds, 3methyladenine the early stage of autophagy inhibitor was used. The result showing the levels of p62 were reversed by the 3-methyladenine treatment in the cells treated with these three compounds confirmed that these three compounds indeed induce autophagy pathway in the CL1-5 cells. Interestingly, the level of p62 was not completely reversed in KB-treated cells. One possibility is the concentration of the inhibitor is not enough to block completely the induction of the autophagy induced by KB. Another possibility is that $\mathrm{KB}$ also induces a downstream signaling pathway beyond the inhibition of 3-methyladenine.

\section{Discussion}

In other cancer cells, cytotoxicity of $\mathrm{KB}, \mathrm{KA}$ and $\mathrm{BC}$ were reported previously and their $\mathrm{IC}_{50}$ were showed at very low concentrations [17]. Moreover, the apoptotic cell death was shown to induce by KB, 
KA and BC to HL-60 cells [17]. This study is the first time report that the cell viability of CL1-5 highly metastatic human lung cancer cells is remarkably decreased when treated with $\mathrm{KB}, \mathrm{KA}$ or $\mathrm{BC}$. The $\mathrm{IC}_{50}$ for $24 \mathrm{hr}$ of KB, KA and BC treatment to CL1-5 cells are 90.8, 114.18 and $162.49 \mathrm{nM}$, respectively. Numerous studies showed that apoptosis or a reciprocal action between apoptosis and autophagy is the major process to control cell fates $[8,9,12,24,25]$. Interestingly, the findings of this study showed that bufadienolides KB, KA, and BC do not induce cellular apoptosis but only induced cell autophagy.

The autophagy was confirmed by showing down-regulation of p-mTOR and up-regulation of LC3-II, Beclin-1, Atg5 and Atg7 in CL1-5 cells. In addition, the 3-methyladenine inhibitor was used to confirm the autophagy induction and also revealed that $\mathrm{KB}, \mathrm{KA}$, and $\mathrm{BC}$ act in the early stage of the autophagy process. In addition, KB also acts in the late stage of the autophagy process as 3-methyladenine inhibitor did not completely restore the content of $\mathrm{p} 62$, which is degraded in the very late stage of the autophagy. Our finding indicated for the first time that bufadienolides induce cell autophagy rather than apoptosis and $\mathrm{KB}$ exhibits the best induction activity in lung adenocarcinoma CL1-5 cells.

Comparing these three bufadienolide derivatives, BC contains a special 1,3,5-orthoacetate group, however, $\mathrm{BC}$ did not exhibit a better cytotoxic activity than $\mathrm{KB}$ and $\mathrm{KA}$, suggesting that the 1,3,5orthoacetate group is not an essential structure to perform the high cytotoxicity of the bufadienolide derivatives. This result is consisting of the previous finding of apoptosis induction in other cancer cells [17]. KB and KA containing a saccharide showed a higher cytotoxicity and autophagy induction, suggesting that a saccharide located at C-3 is able to increase its cytotoxic efficacy. This result is also 
consisting with the previous finding of apoptosis induction in other cancer cells [17]. Moreover, a

hydroxyl group rather than an acetoxy group located at C-3' exhibits a higher efficiency.

Autophagy was thought to be a cellular cytoprotective process to degrade damaged organelles and recycle proteins to against some stresses $[26,27,28]$. In some cases, autophagy and apoptosis modulate each other to control cell fates [24,25,29]. It has also been known that autophagy acts as a pro-death pathway and is called autophagic cell death which is different from apoptotic cell death [30, 31].

Interestingly, the findings in this study, the cell death caused by bufadienolides $\mathrm{KB}, \mathrm{KA}$, and $\mathrm{BC}$ almost did not induce cellular apoptosis but only induced cell autophagy. The result is similar to that a bufadienolide, bufalin, only triggers autophagy in human colon cancer HT-29 and Caco-2 cells [14]. As the close interplay between autophagy and apoptosis processes is crucial in the pathophysiology of nonsmall-cell lung cancer [29], KB, KA, and BC will be the potential drugs that can raise a synergetic effect with conventional anticancer drugs which mainly induce apoptosis pathway. This will be a very interesting issue to be demonstrated for the further study.

\section{Conclusion}

Kalantuboside B, kalantuboside A and bryotoxin C, isolated from Kalanchoe tubiflora (Harvey) activated autophagy process to induce cell death in CL1-5 highly metastatic human lung cancer cells. Among these three compounds, kalantuboside B exhibited a better autophagy induction and cytotoxicity. 
This study provided evidence for the possibility of treating highly metastatic human lung cancer with bufadienolides.

\section{Acknowledgments}

This work is supported by grants from National Science Council (NSC 102-2628-B-039-003-MY2 and MOST 105-2320-B-039-012-MY3). Experiments were performed in part through the use of the Medical Research Core Facilities Center, Office of Research \& Development at China Medical University, Taichung, Taiwan, R.O.C.

\section{Conflict of interest}

The authors declare that they have no conflicts of interest.

\section{References}

1. Gao, H.; Popescu, R.; Kopp, B.; Wang, Z. Bufadienolides and their antitumor activity, Nat. Prod. Rep. 2011, 28, 953-969.

2. Huimin, G.; Martin, Z.; Alexander, L.; Xiyan, W.; Zhimin, W.; Brigitte, K. Comparison of toadvenoms from different Bufo species by HPLC and LC-DAD-MS/MS, J. Ethnopharmacol. 2010, 131, 368-376. 
3. Dan, L.; Xiujuan, Q.; Kezuo, H.; Ye, Z.; Qian, D.; Yuee, T.; Jingdong, Z.; Yunpeng, L. PI3K/Akt is involved in bufalin-induced apoptosis in gastric cancer cells, Anti-Cancer Drugs 2009, 20, 59-64.

4. Kawazoe, N.; Watabe, M.; Masuda, Y.; Nakajo, S.; Nakaya, K. Tiam1 is involved in the regulation of bufalin-induced apoptosis in human leukemia cells, Oncogene 1999, 18, 2413-2421.

5. Watabe, M.; Ito, K.; Masuda, Y.; Nakajo, S.; Nakaya, K. Activation of AP-1 is required for bufalininduced apoptosis in human leukemia U937cells, Oncogene 1998, 16, 779-787.

6. Zhu, L.; Chen, Y.; Wei, C.; Yang, X.; Cheng, J.; Yang, Z.; Chen, C.; Ji, Z. Anti-proliferative and proapoptotic effects of cinobufagin on human breast cancer MCF-7 cells and its molecular mechanism, Nat. Prod. Res. 2018, 32, 493-497.

7. Tsai, S.C.; Yang, J.S.; Peng, S.F.; Lu, C.C.; Chiang, J.H.; Chung, J.G.; Lin, M.W.; Lin, J.K.; Amagaya, S.; Chung, C.W.S.; Tung, T.T.; Huang, W.W.; Tseng, M.T. Bufalin increases sensitivity to AKT/mTOR-induced autophagic cell death in SK-HEP-1 human hepatocellular carcinoma cells, Int. J. Oncol. 2012, 41, 1431-1442.

8. Qi, F.; Inagaki, Y.; Gao, B.; Cui, X.; Xu, H.; Kokudo, N.; Li, A.; Tang, W. Bufalin and cinobufagin induce apoptosis of human hepatocellular carcinoma cells via Fas- and mitochondria-mediated pathways, Cancer Sci. 2011, 102, 951-958.

9. Liu, M.; Feng, L.X.; Hu, L.H.; Liu, X.; Guo, D.A. Advancement in research of anti-cancer effects of toad venom (ChanSu) and perspectives, Modern Research on Chinese Materia Medica 2014, doi: 10.15806/j.issn.2311-8571.2014.0024. 
10. Han, K.Q.; Huang, G.; Gu, W.; Su, Y.H.; Huang, X.Q.; Ling, C.Q. Anti-tumor activities and apoptosis-regulated mechanisms of bufalin on the orthotopic transplantation tumor model of human hepatocellular carcinoma in nude mice, World J. Gastroenterol. 2007, 13, 3374-3379.

11. Wu, S.H.; Bau, D.T.; Hsiao, Y.T.; Lu, K.W.; Hsia, T.C.; Lien, J.C.; Ko, Y.C.; Hsu, W.H.; Yang, S.T.; Huang, Y.P.; Chung, J.G. Bufalin induces apoptosis in vitro and has Antitumor activity against human lung cancer xenografts in vivo, Environ. Toxicol. 2017, 32, 1305-1317.

12. Zhang, G.; Wang, C.; Sun, M.; Li, J.; Wang, B.; Jin, C.; Hua, P.; Song, G.; Zhang, Y.; Nguyen, L.L.; Cui, R.; Liu, R.; Wang, L.; Zhang, X. Cinobufagin inhibits tumor growth by inducing intrinsic apoptosis through AKT signaling pathway in human nonsmall cell lung cancer cells, Oncotarget 2016, 7, 28935-28946.

13. Meng, Z., Yang, P.; Shen, Y.; Bei, W.; Zhang, Y.; Ge, Y.; Newman, R.A.; Cohen, L.; Liu, L.; Thornton, B.; Chang, D.Z.; Liao, Z.; Kurzrock, R. Pilot study of Huachansu in patients with hepatocellular carcinoma, non-small cell lung cancer, or pancreatic cancer, Cancer 2009, 115, 5309_ 5318.

14. Xie, C.M.; Chan, W.Y.; Yu, S.; Zhao, J.; Cheng, C.H. Bufalin induces autophagy-mediated cell death in human colon cancer cells through reactive oxygen species generation and JNK activation, Free Radical Biol. Med. 2011, 51, 1365-1375.

15. Paez, J.G.; Janne, P.A.; Lee, J.C.; Tracy, S.; Greulich, H.; Gabriel, S.; Herman, P.; Kaye, F.J.; Lindeman, N.; Boggon, T.J.; Naoki, K.; Sasaki, H.; Fujii, Y.; Eck, M.J.; Sellers, W.R.; Johnson, B.E.; 
Meyerson, M. EGFR mutations in lung cancer: correlation with clinical response to gefitinib therapy, Science 2004, 304, 1497-1500.

16. Pao, W.; Miller, V.; Zakowski, M.; Doherty, J.; Politi, K.; Sarkaria, I.; Singh, B.; Heelan, R.; Rusch, V.; Fulton, L.; Mardis, E.; Kupfer, D.; Wilson, R.; Kris, M.; Varmus, H. EGF receptor gene mutations are common in lung cancers from "never smokers" and are associated with sensitivity of tumors to gefitinib and erlotinib, Proc. Natl. Acad. Sci. USA 2004, 101, 13306-13311.

17. Huang, H.C.; Lin, M.K.; Yang, H.L.; Hseu, Y.C.; Liaw, C.C.; Tseng, Y.H.; Tsuzuki, M.; Kuo, Y.H. Cardenolides and bufadienolide glycosides from Kalanchoe tubiflora and evaluation of cytotoxicity, Planta Med. 2013, 79, 1362-1369.

18. Chen, Y.K.; Wang, H.C.; Ho, C.T.; Chen, H.Y.; Li, S.; Chan, H.L.; Chung, T.W.; Tan, K.T.; Li, Y.R.; Lin, C.C. 5-demethylnobiletin promotes the formation of polymerized tubulin, leads to G2/M phase arrest and induces autophagy via JNK activation in human lung cancer cells, J. Nutr. Biochem. 2015 , $26,484-504$.

19. Tanida, I.; Ueno, T.; Kominami, E. LC3 conjugation system in mammalian autophagy, Int. J. Biochem. Cell Biol. 2004, 36, 2503-2518.

20. Das, G.; Shravage, B.V.; Baehrecke, E.H. Regulation and function of autophagy during cell survival and cell death, Cold Spring Harb. Perspect Biol. 2012, 4: a008813.

21. Kim, J.; Kundu, M.; Viollet, B.; Guan, K.L. AMPK and mTOR regulate autophagy through direct phosphorylation of Ulk1. Nat. Cell Biol. 2011, 13, 132-141. 
22. Denton, D.; Xu, T.; Kumar, S. Autophagy as a pro-death pathway, Immunol. Cell Biol. 2015, 93, 3542.

23. Bjørkøy, G.; Lamark, T.; Brech, A.; Outzen, H.; Perander, M.; Overvatn, A.; Stenmark, H.; Johansen, T. p62/SQSTM1 forms protein aggregates degraded by autophagy and has a protective effect on huntingtin-induced cell death, J. Cell Biol. 2005, 171, 603-614.

24. Su, M.; Mei, Y.; Shinha, S. Role of the crosstalk between autophagy and apoptosis in cancer, $J$. Oncol. 2013, 2013:102735.

25. El-Khattouti, A.; Selimovic, D.; Haikel, Y.; Hassan, M. Crosstalk between apoptosis and autophagy: molecular mechanisms and therapeutic strategies in cancer, J. Cell Death. 2013, 6, 37-55.

26. Kondo, Y.; Kanzawa, T.; Sawaya, R.; Kondo, S. The role of autophagy in cancer development and response to therapy. Nat. Rev. Cancer 2005, 5, 726-734.

27. Levine, B. Cell biology: autophagy and cancer, Nature 2007, 446, 745-747.

28. Song, J.; Qu, Z.; Guo, X.; Zhao, Q.; Zhao, X.; Gao, L.; Sun, K.; Shen, F.; Wu, M.; Wei, L. Hypoxiainduced autophagy contributes to the chemoresistance of hepatocellular carcinoma cells, Autophagy 2009, 5, 1131-1144.

29. Liu, G.; Pei, F.; Yang, F.; Li, L.; Amin, A.D.; Liu, S.; Buchan, J.R.; Cho, W.C. Role of autophagy and apoptosis in non-small-cell lung cancer, Int. J. Mol. Sci. 2017, 18, pii: E367. doi: 10.3390/ijms 18020367.

30. Schweichel, J.U.; Merker, H.J. The morphology of various types of cell death in prenatal tissues, 
Teratology 1973, 7, $253-266$.

31. Das, G.; Shravage, B.V.; Baehrecke, E.H. Regulation and function of autophagy during cell survival and cell death, Cold Spring Harb. Perspect Biol. 2012, 4: a008813.

\section{Figure Legends}

Figure 1. Structures of the three bufadienolides used in this study.

Figure 2. Cell viability assays. CL1-5 cells were treated with different concentrations of kalantuboside B (KB), kalantuboside A (KA) and bryotoxin C (BC) for $24 \mathrm{hr}$, and then assessed by the MTT assay. Data are presented the mean \pm S.D. of triplicate wells. The $\mathrm{IC}_{50}$ values were calculated as $52.30 \pm 1.8 \mathrm{ng} / \mathrm{ml}$ $(90.8 \mathrm{nM}), 70.56 \pm 5.7 \mathrm{ng} / \mathrm{ml}(114.18 \mathrm{nM})$ and $76.70 \pm 1.3 \mathrm{ng} / \mathrm{ml}(162.49 \mathrm{nM})$ for KB, KA and $\mathrm{BC}$, respectively.

Figure 3. Annexin V-FITC and PI analyses. CL1-5 cells were treated with $100 \mathrm{nM}$ of KB, KA and BC for $24 \mathrm{~h}$, respectively. The horizontal and vertical axes represent labeling with Annexin V-FITC and Propidium Iodide-PE, respectively. The lower right part represents early apoptotic cells (positive for Annexin V only). The upper right part represents late apoptotic cells (positive for both Annexin V and PI). 
Figure 4. Cell cycle analyses. CL1-5 cells were treated with KB, KA and BC (100 nM) for 24 hrs, respectively. Cell cycle distributions were determined by propidium iodide staining and subsequent flow cytometry analysis.

Figure 5. Autophagosomes measured by acridine orange staining. CL1-5 cells were treated $100 \mathrm{nM}$ $\mathrm{KA}, \mathrm{KB}$ and $\mathrm{BC}$ for 24 hrs, respectively, and then subjected to acridine orange staining and flow cytometry assays.

Figure 6. LC3-GFP puncta analyses in transfected CL1-5 lung adenocarcinoma cells. The CL1-5 cells transfected with LC3-GFP plasmid were treated with $100 \mathrm{nM}$ of KB, KA and BC with $50 \mathrm{nM}$ rapamycin in the CL1-5 cells for 24hr, respectively. The green fluorescence in the transfected cells was observed and detected by confocal microscopy.

Figure 7. The expression levels of autophagy-related proteins. Cells were treated with $50 \mathrm{nM}$ rapamycin, $100 \mathrm{nM} \mathrm{KB}, \mathrm{KA}$ and $\mathrm{BC}$ respectively. The antibody used for the western blot indicated at the right. The intensity of the band was quantitatively determined with ImageJ software. The ratios were determined by normalizing the intensity of the target bands with that of $\beta$-actin. Experiments were repeated three times with reproducible results. 
Figure 8. The decreases of p62 were reversed by the inhibitor 3-MA. The CL1-5 cells were treated with $100 \mathrm{nM}$ of $\mathrm{KB}, \mathrm{KA}$ or $\mathrm{BC}$, and with or without $5 \mathrm{mM}$ of 3-MA for $24 \mathrm{hr}$, respectively. The intensity of the band was quantitatively determined with ImageJ software. The ratios were determined by normalizing the intensity of the target bands with that of $\beta$-actin. Experiments were repeated three times with reproducible results. 
Fig. 1
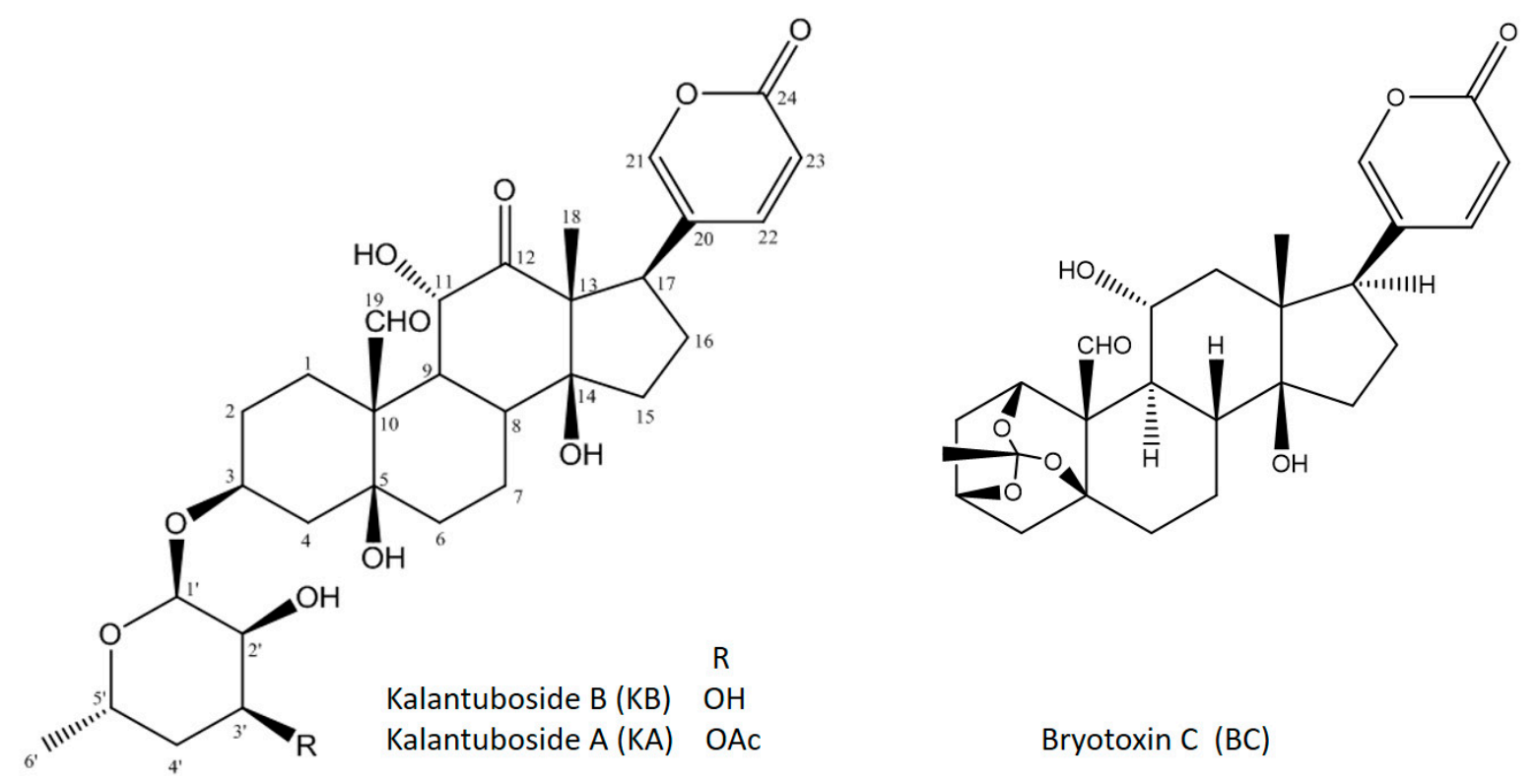

Bryotoxin C (BC) 
Fig. 2

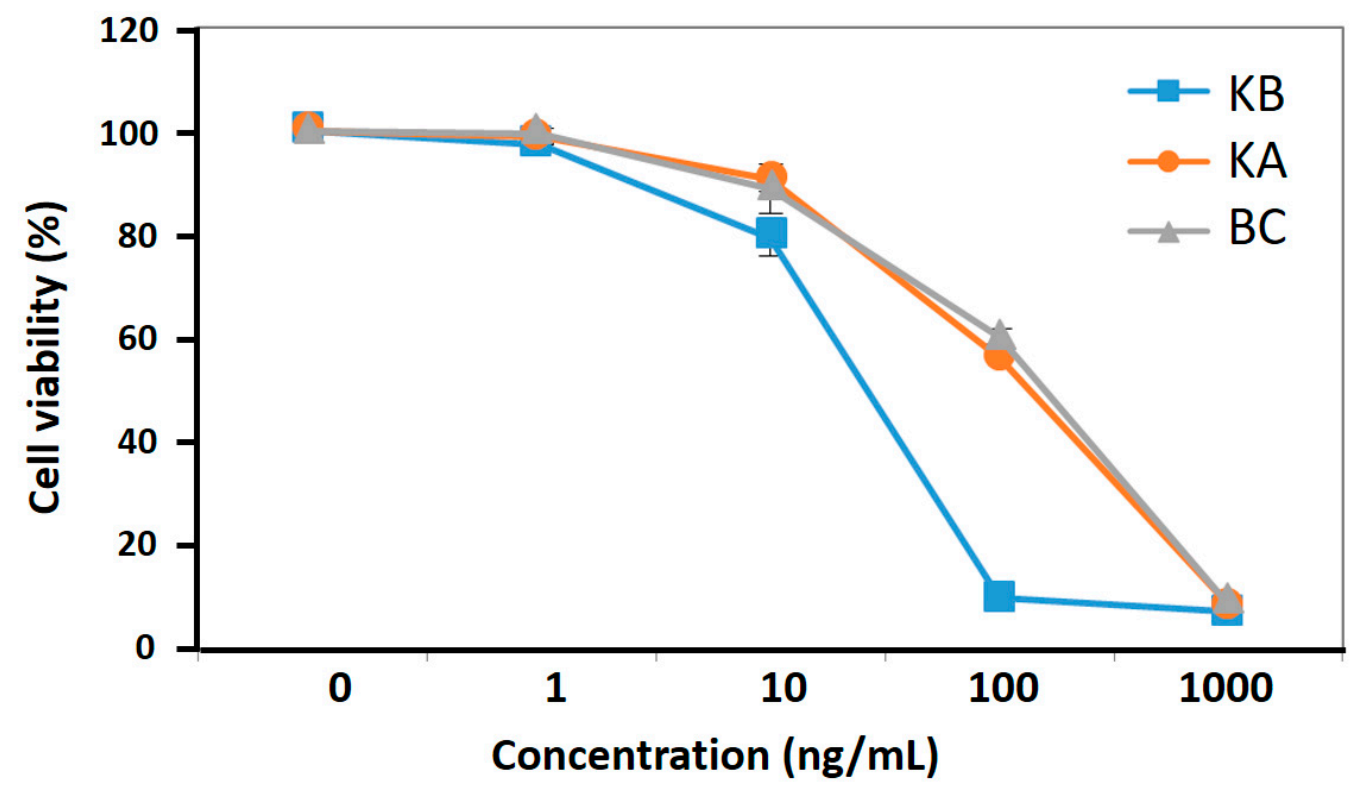


Fig. 3
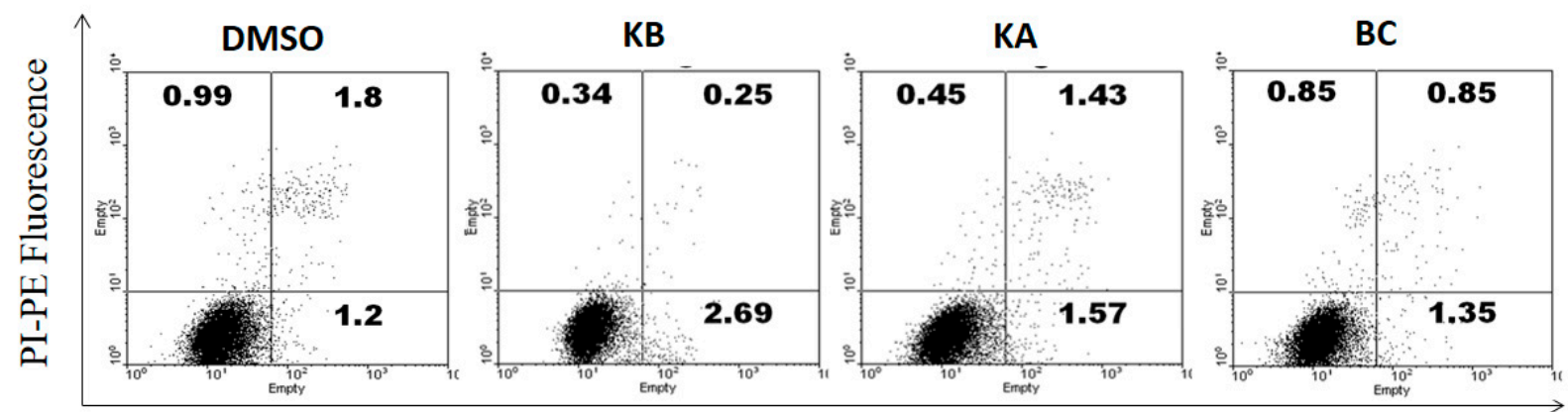

Annexin V-FITC Fluorescence 
Fig. 4

DMSO

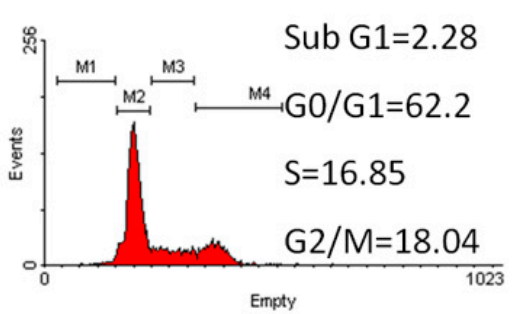

BC

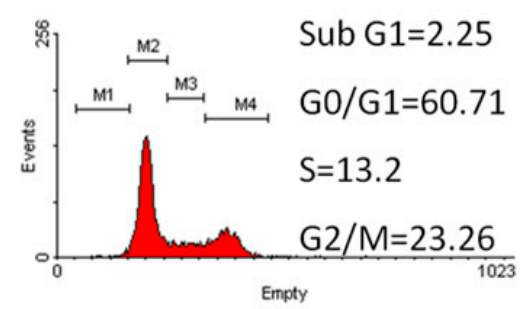

KB
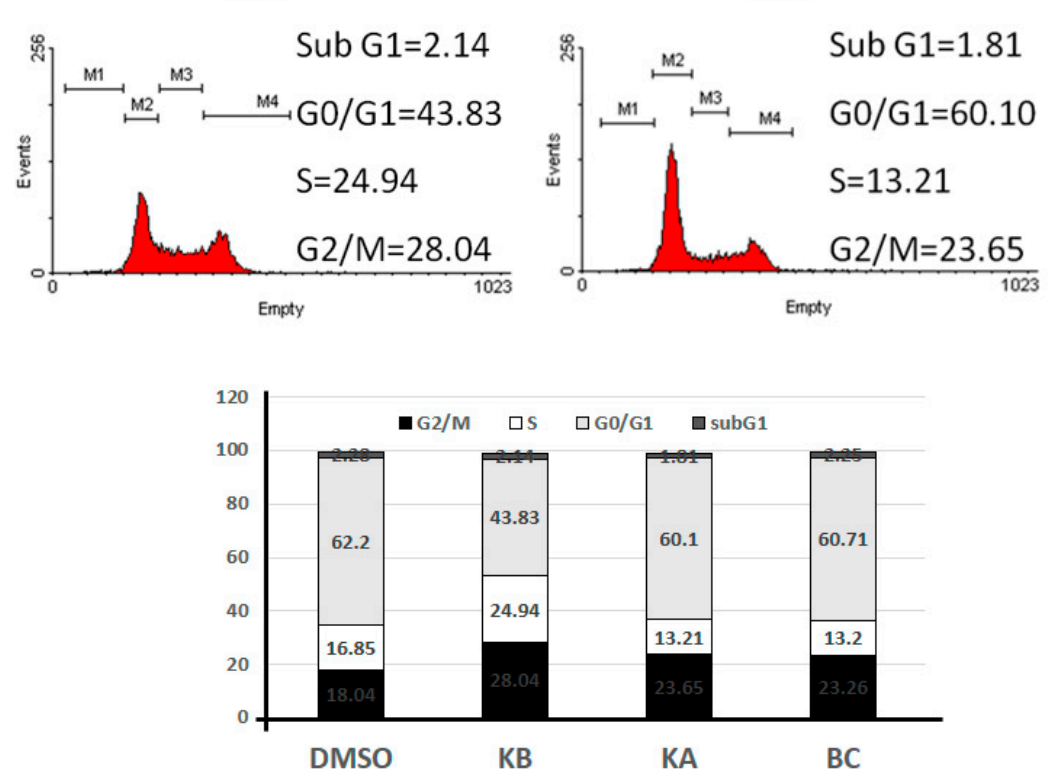
Fig. 5

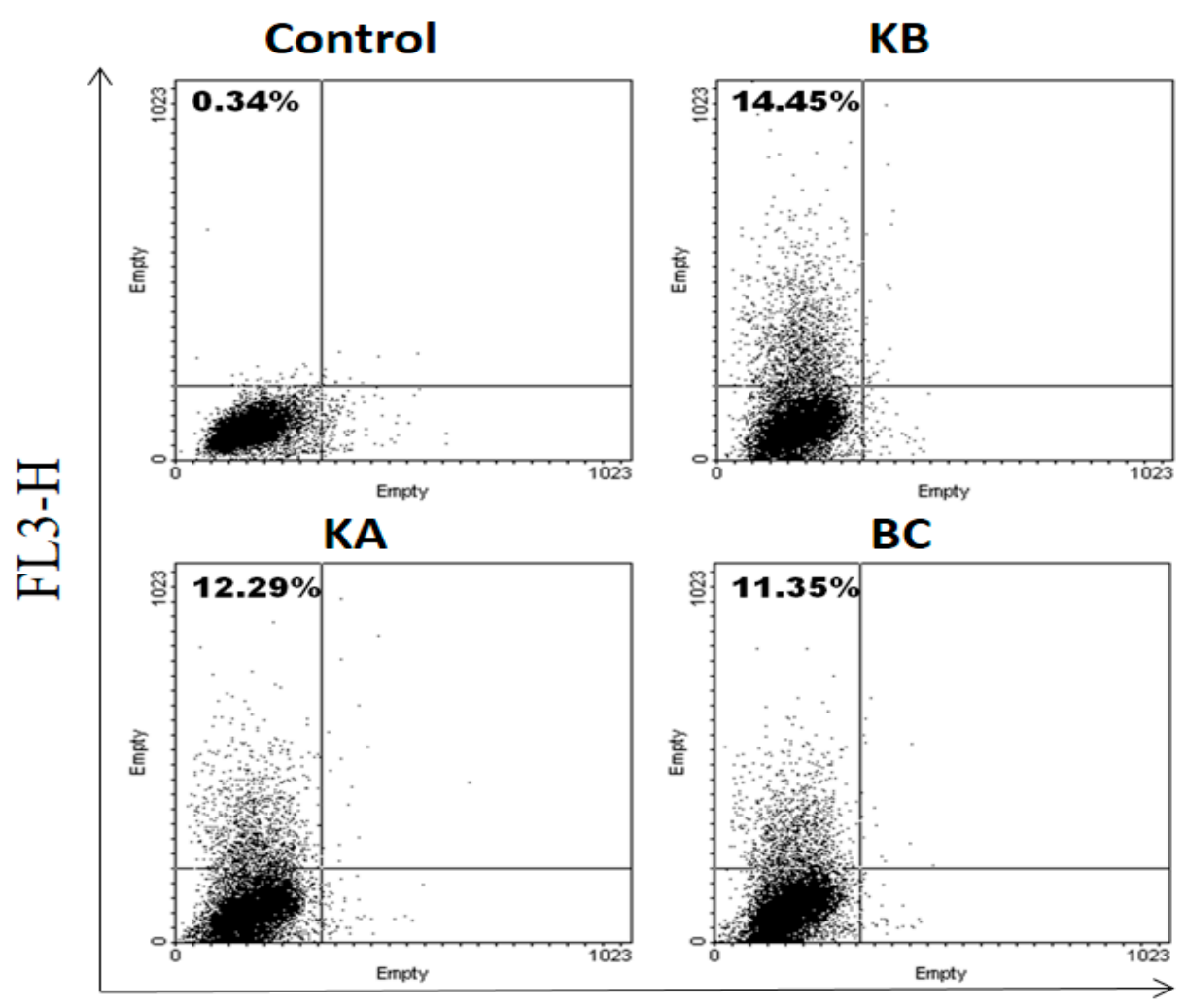

FL1-H 
Fig. 6
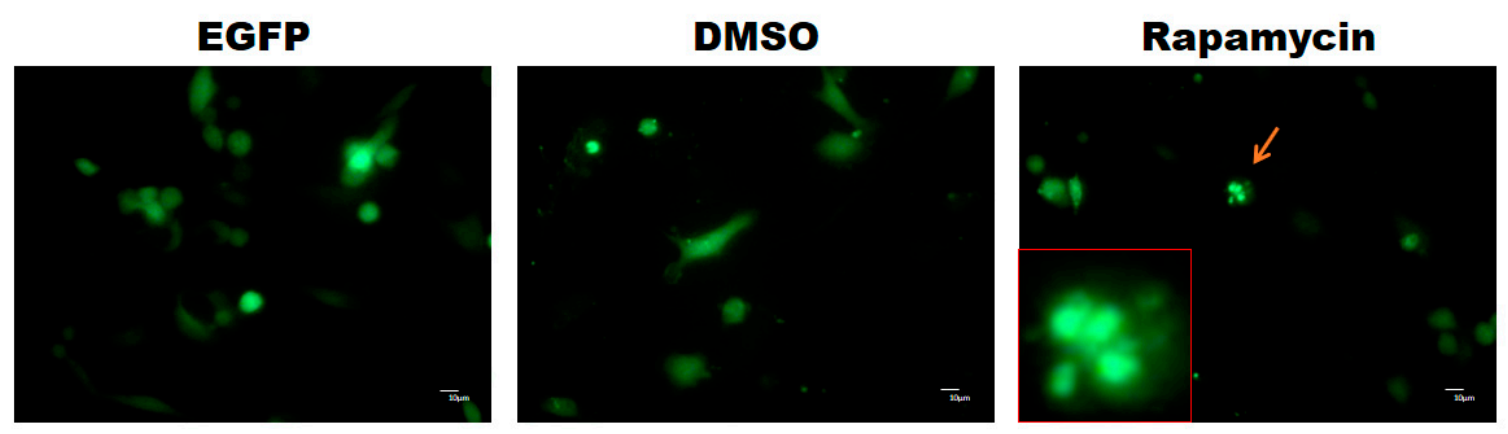

KB

KA
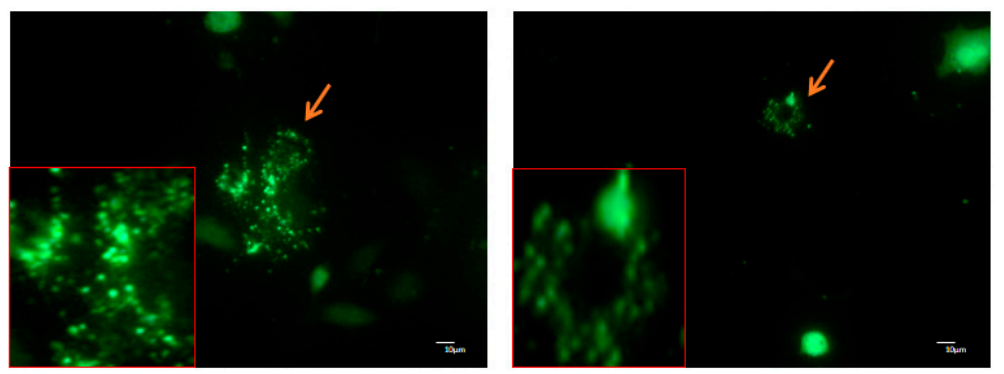

BC

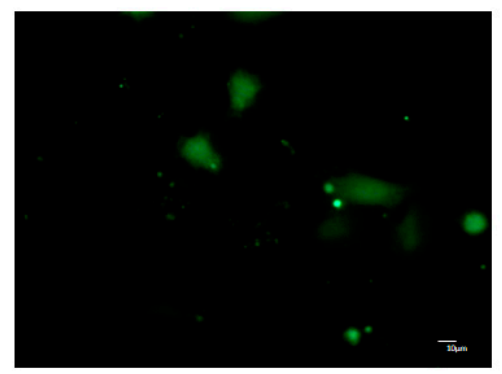


Fig. 7

\begin{tabular}{|c|c|c|c|c|c|c|}
\hline \multirow{2}{*}{\multicolumn{2}{|c|}{ DMSO }} & Rapamycin & KB & KA & $\mathrm{BC}$ & \multirow[b]{2}{*}{ p-mTOR } \\
\hline & & 2 & 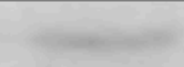 & $=$ & $\mathrm{s}$ & \\
\hline \multirow[t]{2}{*}{ Fold } & 1 & 0.26 & 0.08 & 0.31 & 0.58 & \\
\hline & & & -1 & $=$ & $\longrightarrow$ & $\begin{array}{l}\text { LC3-I } \\
\text { LC3-II }\end{array}$ \\
\hline \multirow{3}{*}{ Fold } & 1 & 1.69 & 0.93 & 0.69 & 1.03 & \\
\hline & 1 & 1.3 & 2.55 & 1.84 & 2.36 & \\
\hline & & \multicolumn{4}{|c|}{ 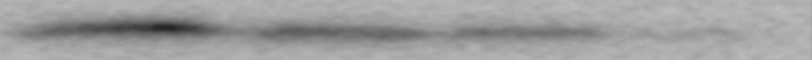 } & Beclin 1 \\
\hline \multirow[t]{2}{*}{ Fold } & 1 & 16.57 & 12.86 & 10.47 & 3.2 & \\
\hline & $=$ & - & $=$ & $=$ & - & Atg 7 \\
\hline \multirow[t]{2}{*}{ Fold } & 1 & 1.26 & 1.76 & 1.18 & 1.18 & \\
\hline & 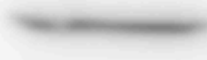 & $\longrightarrow$ & - & 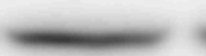 & 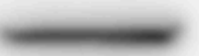 & Atg 5 \\
\hline Fold & 1 & 2.17 & 2.77 & 1.51 & 2.01 & \\
\hline
\end{tabular}


Fig. 8

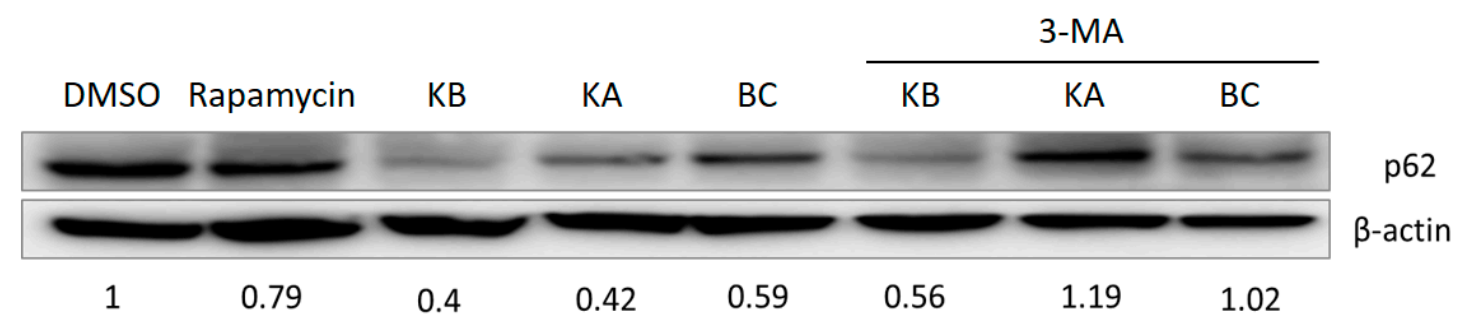

